\title{
E्己ucká̃ \\ A Cidade como Espaço da Infância
}

\author{
Rhaisa Naiade Pael Farias' \\ Fernanda Müiller
}

'Universidade de Brasília (UnB), Brasília/DF - Brasil

RESUMO - A Cidade como Espaço da Infância' ${ }^{1}$ Estudos recentes (Valentine, 1997; Mikkelsen; Christensen, 2009) têm sugerido que a experiência da infância contemporânea nos centros urbanos é cada vez mais vivida de forma fragmentada. Para investigar tal afirmativa, o presente artigo se propõe a conhecer as experiências urbanas de duas meninas e dois meninos, habitantes de Brasília, Distrito Federal. O estudo utilizou métodos visuais e considerou as crianças como principais informantes. Map-like model (Blaut et al., 2003) e a foto-elicitação (Clark-Ibáñez, 2004) foram considerados como instrumentos de geração de dados. A análise sugere que apesar das crianças serem dirigidas aos espaços especializados e privados, seu conhecimento da cidade não é limitado.

Palavras-chave: Cidade. Infância. Educação Não-Formal. Métodos Visuais.

ABSTRACT - The City as a Childhood Space. Recent studies (Valentine, 1997; Mikkelsen; Christensen, 2009) have suggested that the experience of contemporary childhood in urban centers is increasingly lived in a fragmented way. In order to investigate such claim, this article aims to know the urban experiences of two girls and two boys who live in Brasília, Federal District, Brazil. The study considered visual methods and the children were understood as key informants. Map-like model (Blaut et al., 2003) and photo-elicitation (Clark-Ibáñez, 2004) were considered as tools for data generation. The analysis suggests that although children are directed to specialized and private spaces, their knowledge of the city is not limited.

Keywords: City. Childhood. Non-Formal Education. Visual Methods.

Educação \& Realidade, Porto Alegre, v. 42, n. 1, p. 261-282, jan./mar. 2017. 


\section{Uma Breve Introdução de Onde Partimos}

O presente artigo explora a compreensão de quatro crianças sobre a cidade. Para tanto, as experiências urbanas de duas meninas e dois meninos de cinco anos, habitantes de Brasília/Distrito Federal, foram tratadas a partir de seus pontos de vista, respeitando elaborações e tempos próprios. Aliadas às explicações das crianças foram incorporadas informações referentes à mobilidade na cidade, fornecidas por suas responsáveis ${ }^{2}$, que, de maneira complementar, indicaram trajetos percorridos por seus filhos.

Os resultados aqui apresentados derivam de um estudo mais abrangente, desenvolvido com vistas a contribuir com o preenchimento de uma lacuna que envolve a temática infância e cidade nas Ciências Humanas e Sociais. A pesquisa discutiu a organização da cidade, as possíveis aprendizagens que podem ocorrer no meio urbano (Nunes, 2003) e o potencial das crianças pequenas serem consultadas a respeito de temas que afetam diretamente as suas vidas.

O presente artigo afilia-se aos Estudos Sociais da Infância, o que tem relação direta com escolhas teóricas e metodológicas aqui tratadas. Apresentaremos a discussão de dados decorrentes de uma investigação qualitativa, conduzida ao longo de 2013, e que buscou a ampla participação das crianças. O processo investigativo estabeleceu prioritariamente uma relação interativa e menos hierárquica entre pesquisadora e crianças e não teve a pretensão de produzir qualquer generalização ou representatividade sobre as suas experiências na cidade.

Partimos do pressuposto de que a pesquisa participativa deve ser organizada com base em um desenho teórico-metodológico que evidencie as potencialidades das crianças durante todo o processo. Por este motivo, optamos pela incorporação de métodos visuais por serem apropriados para explorar sensações e emoções, estimular o participante a acessar distintas dimensões de sua experiência de vida e comunicar-se por meio de diferentes linguagens, que não somente a oral (Pink, 2011).

Todavia, reconhecemos que a investigação com crianças pequenas ainda apresenta um conjunto de desafios, a começar pela questão ética envolvida. Morrow e Richards (1996) afirmam que um dos obstáculos éticos na pesquisa com crianças está em implementar estratégias que respeitem os seus pontos de vista. Nesse sentido, não basta obter a aprovação de um Comitê de Ética, mas assumir as crianças como competentes durante todas as etapas da pesquisa. A partir desse pressuposto, Morrow e Richards (1996) insistem que crianças devem ser consultadas a respeito de seu interesse em participar da pesquisa e informadas sobre a possibilidade de uma eventual desistência ${ }^{3}$.

A cidade é um espaço não formal de educação que proporciona diferentes aprendizagens quando os habitantes se relacionam com a sua estrutura. Trata-se de uma criação humana composta pelo plural de praças, ruas, avenidas e, também, por características singulares, como esquinas, becos e cantos. Portanto, a cidade é um núcleo vivo (Freitag, 2002). Nesse sentido, não pode ser entendida apenas como um lugar de 
passagem, mas de interação, de comunicação e de encontro de seus habitantes, e destes com o meio. Tal premissa é válida não só para adultos, mas também para crianças, que a partir de ações cotidianas podem experimentar, explorar e aprender no e com o meio urbano.

Estudos de diferentes áreas das Ciências Humanas e Sociais (Valentine, 1997; Karsten; Van Vliet, 2006; Mikkelsen; Christensen, 2009; Broberg; Kyttä; Fagerholm, 2013) mostram que a experiência da infância urbana contemporânea aproxima-se cada vez mais ao estilo de vida dos adultos que vivem a cidade de maneira fragmentada. Enquanto a cidade concentra recursos e atividades em espaços específicos, adultos têm sua mobilidade associada ao uso de automóveis (Sennet, 2008). Essa compartimentação da cidade nos leva a crer que, ao invés de pertencer a todos, cidades têm segregado as crianças a espaços especializados e privados (Ward, 1978; Tonucci, 1996; Rasmussen; Smidt, 2003).

O confinamento das crianças em espaços especializados e privados está ligado à preocupação dos adultos em assegurar proteção às crianças. Entretanto, a falta de contato com espaços públicos e não especializados pode vir a afastar as crianças da convivência com outros grupos geracionais e propiciar uma visão limitada da cidade. Espaços vazios, calçadas, ruas, esquinas e cantos podem ser ao mesmo tempo convenientes e interessantes. Ward (1978), Jacobs (2000) e Tonucci (1996) afirmam que espaços públicos e não especializados proporcionam uma variedade de experiências e permitem que crianças tomem suas próprias decisões, uma vez que não sofrem a predeterminação de como devem ou não ser utilizados.

Exemplifica Castro (2004) que, para algumas crianças do Rio de Janeiro, a rua é lugar de convergência da pluralidade e da diferença, da descoberta e da convivência, da aprendizagem e do deslocamento. Ainda, Müller (2007) destaca que, em certas situações, a rua é indicada pela criança como uma extensão da casa, um lugar de encontro para brincar e conversar. Desse modo, a afirmativa de que crianças de zonas urbanas vivenciam menos os espaços públicos não é universal, mas pode variar de cidade para cidade, de bairro para bairro, a depender dos grupos sociais que ali habitam.

A seguir, o texto está organizado em quatro seções. A primeira seção explora o repertório teórico-metodológico implementado na investigação e apresenta os aspectos da construção do map-like model (Blaut et al., 2003) e da foto-elicitação (Clark-Ibáñez, 2004) que foram utilizados. A segunda seção descreve os resultados obtidos no processo de geração de dados com as crianças. A terceira seção apresenta inicialmente o mapa dos trajetos mais comuns percorridos pelas crianças e, em seguida trata os resultados sobre a mobilidade das crianças na cidade. A quarta seção aborda breves conclusões.

\section{Aspectos Teórico-Metodológicos da Pesquisa}

A premissa de que a infância é mais do que um período de desenvolvimento na vida do ser humano tem sido reafirmada ao longo dos 
anos no campo dos Estudos Sociais da Infância (Prout; James, 1990; Bluebond-Langner; Korbin, 2007; Mizen; Ofusi-Kusi, 2013). Está amplamente reconhecida neste campo a ideia de que crianças são competentes, que inventam, transformam, compartilham e participam da cultura com seus pares e com adultos (Corsaro, 1997).

O reconhecimento da infância como uma categoria socialmente construída é um ponto crucial deste trabalho e nos alinha ao paradigma proposto por James e Prout (1990). Como já argumentado por Müller e Nunes (2014), James e Prout (1990) compilaram neste novo paradigma o interacionismo e o construcionismo social, aliados a uma nova visão sobre a infância. A partir do primeiro, os autores construíram a noção de criança como simultaneamente agente e produto dos processos sociais; inspirado no segundo consideraram a variabilidade social, cultural e histórica da infância, o que desconstruiu a sua natural associação a aspectos biológicos (James; Prout, 1990). Também ao encontro do paradigma, temos interesse nos sentidos atribuídos pelas crianças à cidade, o que motivou a elaboração do desenho teórico-metodológico deste estudo.

O desenvolvimento de uma investigação com a participação das crianças exige do pesquisador um contínuo exercício reflexivo, que pressupõe a problematização tanto da posição social da criança quanto da adequação da metodologia proposta (Christensen; James, 2008; Punch, 2002). Planejamos a utilização de métodos que proporcionassem um alto grau de participação das crianças, desde a geração dos dados até a sua interpretação (Young; Barrett, 2001; Clark, 2010). Apelamos assim aos métodos visuais, pois estes encorajam a participação direta das crianças e podem gerar conhecimento de forma mais democrática, uma vez que incluem ambas as perspectivas, ou seja, a das crianças e dos adultos (Clark, 2010).

Ao tratar as crianças como agentes sociais competentes, entendemos que elas são capazes de fornecer uma perspectiva única sobre seu mundo social (Einarsdóttir, 2007; Darbyshire; Macdougall; Schiller, 2005). Por este motivo, suas narrativas, gestos e expressões foram amplamente exploradas nesta pesquisa. Nessa perspectiva as crianças são entendidas como copesquisadoras, o que Clark (2010, p. 116, tradução nossa) explica: “[...] o termo copesquisador indica a intenção de compartilhamento pretendido dentro do processo de pesquisa”. Ainda, segundo Alderson (2008, p. 278, tradução nossa):

\section{A participação das crianças em pesquisas pressupõe mu- dar a ênfase de métodos e tópicos. Reconhecer as crianças como copesquisadoras ao invés de apenas objetos de pes- quisa envolve aceitar que as crianças podem 'falar' por si mesmas e relatar pontos de vista e experiências válidos.}

Optar pela participação da criança é uma maneira de assumir que elas possuem conhecimento, poder de decisão, e experiências significativas. Igualmente, considerar crianças como copesquisadoras demanda o reconhecimento de seus direitos ${ }^{4}$. Contudo, não deixamos de 
reconhecer a existência de uma relação de diferença entre pesquisador/ adulto e participante/criança, que é evidente no tamanho físico, no uso de determinado vocabulário, nas relações de poder e de autoridade. Na tentativa de superar este desequilíbrio, os métodos visuais preveem a participação colaborativa de crianças e de pesquisador, evitando assim a sobreposição de um ao outro. Por isso procuramos nos concentrar nas possibilidades de coconstrução de sentidos promovidas pelos métodos visuais (Clark, 2010).

As quatro crianças foram convidadas a participar de três encontros individuais que foram realizados em suas casas. Contamos ao final do trabalho de campo com dados gerados por meio de métodos visuais em um total de 12 encontros. O primeiro encontro previu uma sessão de história; o segundo possibilitou a construção de uma cidade; e o terceiro considerou uma conversa motivada pela foto-elicitação.

Um aspecto básico referente aos métodos visuais é o uso de materiais visuais (Banks, 2004, p. 9) produzidos tanto pelo pesquisador como pelos participantes da pesquisa. Tanto com a utilização do maplike model quanto da foto-elicitação pretendíamos que as crianças participassem simultaneamente da geração e da interpretação dos dados, o que acabou enriquecendo o posterior processo de análise. Além disso, a combinação destes instrumentos na geração de dados requereu a triangulação de informações, a partir da ênfase na voz das crianças. Ao mesmo tempo, possibilitou que as crianças se expressassem de diferentes maneiras, por meio de diversas linguagens, o que deu a elas controle sobre o ritmo dos encontros (Mayall, 2002).

Explicaremos a seguir a proposta de cada um dos encontros, assim como os instrumentos utilizados.

\section{Primeiro Encontro: vida animal e seu poder catalisador}

O primeiro encontro teve o intuito de facilitar o contato com cada uma das crianças e introduzir o tema cidade por meio de uma conversa informal e da utilização das ilustrações de um livro. Para tanto, a história "Aventura Animal" (Vilela, 2013) foi explorada pelas crianças à medida que manusearam o livro, apontaram elementos da história, criaram hipóteses sobre a narrativa e as imagens e comentaram sobre a sua própria rotina na cidade.

A história foi escolhida por apresentar a experiência de vários animais que passeiam pela cidade. Este também foi o momento em que o material para a construção da cidade foi apresentado às crianças, que puderam manuseá-lo livremente.

\section{Segundo Encontro: map-like modele a construção de cidades}

No segundo encontro as crianças foram convidadas a construir uma cidade e todo esse processo foi vídeo gravado. Esta estratégia incorporou o uso de materiais tridimensionais e foi inspirada nos estudos de Blaut et al. (2003), do campo da Geografia. Os autores argumentam 
A Cidade como Espaço da Infância

que a aprendizagem espacial está vinculada às diferentes formas com as quais as crianças se relacionam com o espaço. Para tanto, desenvolveram o conceito de map-like model que:

\begin{abstract}
[...] nos permite estudar as representações materiais que mantêm as propriedades essenciais de um mapa, mas não correspondem à todas as definições cartográficas usuais de um mapa. Queremos explorar as habilidades de mapeamento em crianças que ainda não são alfabetizadas, ou que estão aprendendo a ler. Não podemos, portanto, usar o conceito de mapa, o qual requer que a criança leia formalmente e compreenda as convenções de mapeamento que se tem estabelecidas (Blaut et al., 2003, p. 167, tradução nossa).
\end{abstract}

Logo, os autores afirmam que crianças conseguem construir mapas que interpretam e representam seu contexto, sem necessariamente lançar mão da linguagem convencional dos adultos. Tal afirmativa foi apoiada em pesquisas que os autores supracitados e colaboradores desenvolveram em diferentes países, quando, com a utilização de brinquedos, solicitavam às crianças a construção de paisagens representativas de lugares reais. O resultado dessa construção foi conceituada como map-like model. Por este motivo nos inspiramos neste instrumento, pois nos interessava capturar experiências das crianças no espaço em que vivem e não somente lógicas formais de localização de prédios e ruas.

Todavia, não seguimos exatamente o protocolo do map-like model. Blaut e Stea (1974) dedicaram-se a uma análise pormenorizada de rotas apresentadas pelas crianças, conduziram um teste de labirinto, e um teste verbal que compreendeu a participação de 80 crianças de 3 a 6 anos. Os autores definiram os brinquedos aos quais as crianças teriam acesso para construir uma cidade, que obrigatoriamente seria posicionada sobre um pedaço de papel de aproximadamente $91 \mathrm{~cm} \mathrm{x} 61 \mathrm{~cm}$ localizado no chão. Ainda, Blaut e Stea (1974) planejaram que a sessão para a construção do map-like model não ultrapassaria 10 minutos. Eles contaram com fotografias que eram disparadas a cada três segundos, gravações de áudio, e notas como formas de registro dos dados.

Já em nosso estudo, cada criança foi convidada a construir uma cidade utilizando como recurso 226 peças, dentre elas, blocos de madeira e artefatos em miniatura (carros, árvores e miniaturas de pontos turísticos) $)^{5}$. Durante esse encontro, as crianças puderam tomar decisões sobre sua construção e conversar livremente com a pesquisadora. Ao término da construção, foram realizadas cinco fotografias, quatro laterais e uma aérea.

Apesar das diferenças entre os materiais, tempo e conduta de nossa pesquisa e aquelas realizadas por Blaut e Stea, nós definitivamente concordamos com a concepção inovadora sobre as crianças que ambos apresentavam já nos anos 1970 . Os autores desafiaram a teoria Piagetiana sobre o desenvolvimento infantil ao mostrar competências complexas de crianças pequenas em relação ao espaço. Assim como eles, tam- 
bém acreditamos que as crianças poderiam contar histórias e perceber macro espaços. A partir desse entendimento, centramo-nos na escuta de histórias sobre as suas experiências nas cidades.

Se uma das premissas do método visual é de utilizar imagens no curso da pesquisa, o map-like model serviu para que as crianças produzissem o conteúdo das imagens que seriam por elas tratadas no encontro subsequente.

\section{Terceiro Encontro: foto-elicitação e as narrativas sobre a cidade}

O terceiro e último encontro foi áudio gravado e teve como objetivo conduzir um exercício de foto-elicitação a partir das fotografias das cidades, construídas no encontro anterior. Destacamos que a foto-elicitação consiste na utilização de imagens como auxiliares para o desencadeamento de uma narrativa. Neste caso, pretendíamos que as fotografias, de cinco diferentes ângulos de cada uma das cidades promovessem uma maior descontração e fluidez na forma de colaboração dos participantes (Banks, 2004). Ainda, como afirma Clark-Ibáñez (2004, p. 1512, tradução nossa), as fotografias podem servir como “[...] uma ferramenta para expandir as perguntas e, simultaneamente, os participantes podem usar fotografias para comunicar de maneira singular dimensões de suas vidas".

A foto-elicitação alinha-se aos pressupostos dos métodos visuais por incentivar uma maior cooperação dos participantes da pesquisa, que neste contexto, também foram considerados copesquisadores. Vale destacar ainda que foi intencional o planejamento deste terceiro encontro. O seu propósito era utilizar as imagens das cidades construídas (ou seja, outra representação) para catalisar narrativas das crianças.

\section{A Cidade Construída e a Cidade Vivida como Resultados da Pesquisa}

Todas as crianças participantes da pesquisa nasceram em Brasília, frequentam a mesma instituição de Educação Infantil e desenvolvem diferentes atividades no contra turno, como por exemplo, natação, musicalização e capoeira. As famílias, cuja composição é nuclear, possuem carro e este é o seu principal meio de transporte.

O Quadro 1 a seguir demonstra sinteticamente os dados referentes a cada uma das cidades construídas pelas crianças ${ }^{6}$ no segundo encontro. 
A Cidade como Espaço da Infância

\section{Quadro 1 - Características das Cidades das Crianças}

\begin{tabular}{|c|c|c|c|c|}
\hline Nome da criança & Amanda & Daniela & Lucas & Greg \\
\hline Tipo da construção & $\begin{array}{c}\text { Empilhada } \\
\text { em cinco } \\
\text { níveis/ } \\
\text { Espalhada }\end{array}$ & $\begin{array}{c}\text { Plana com } \\
\text { um nível/ } \\
\text { Concen- } \\
\text { trada }\end{array}$ & $\begin{array}{c}\text { Empilhada } \\
\text { em dois } \\
\text { níveis/ Con- } \\
\text { centrada }\end{array}$ & $\begin{array}{c}\text { Empilhada } \\
\text { em cinco } \\
\text { níveis/ } \\
\text { Espalhada }\end{array}$ \\
\hline $\begin{array}{c}\text { Quantidade de } \\
\text { peças utilizadas }\end{array}$ & 73 & 124 & 70 & 226 \\
\hline $\begin{array}{c}\text { Tempo da cons- } \\
\text { trução gravada em } \\
\text { vídeo }\end{array}$ & $8 \mathrm{~min}$. & $\begin{array}{c}17 \text { min. } 25 \\
\text { seg. }\end{array}$ & $\begin{array}{c}7 \text { min. } \\
30 \text { seg. }\end{array}$ & $\begin{array}{c}34 \text { min. } 15 \\
\text { seg. }\end{array}$ \\
\hline
\end{tabular}

Fonte: Elaborado pelas autoras com base nos dados de pesquisa.

Podemos observar que as cidades das crianças apresentaram estruturas diversas. Por exemplo, Amanda (Figura 1), Greg (Figura 4) e Lucas (Figura 3) empilharam os materiais disponibilizados, enquanto Daniela (Figura 2) manteve sua construção plana. Amanda e Greg organizaram suas cidades espalhadas, já Daniela e Lucas as mantiveram concentradas em uma pequena área.

Ao examinarmos o tempo que cada criança utilizou para construir a sua cidade e compararmos com a quantidade de peças que utilizaram, constatamos que Lucas foi a criança que utilizou menos peças e menos tempo para realizar a sua construção. Amanda usou três peças e alguns segundos a mais do que Lucas. Daniela investiu dezessete minutos em sua construção e utilizou cento e vinte e uma peças e mais as três tampas das caixas onde os materiais estavam guardados. Greg foi a criança que gastou mais tempo ao construir sua cidade e utilizou todas as peças disponíveis. Portanto, as quatro cidades foram construídas conforme o tempo e a escolha de cada uma das crianças.

Apresentamos a seguir as fotografias das cidades das crianças:

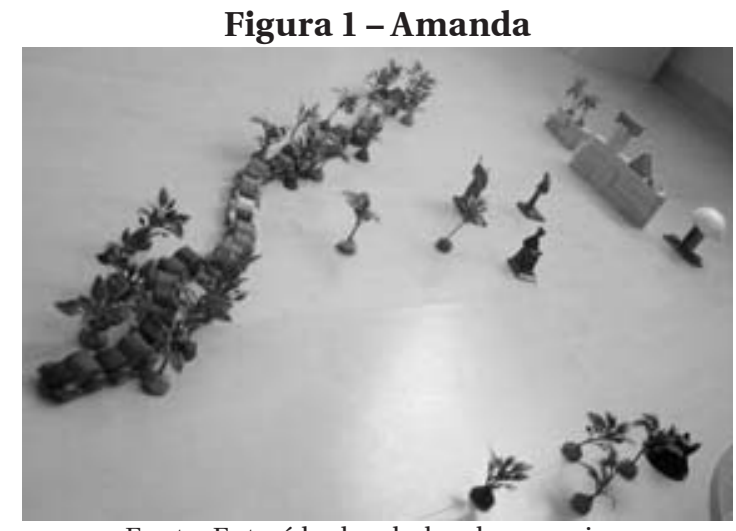

Fonte: Extraído dos dados de pesquisa. 
Figura 2 - Daniela

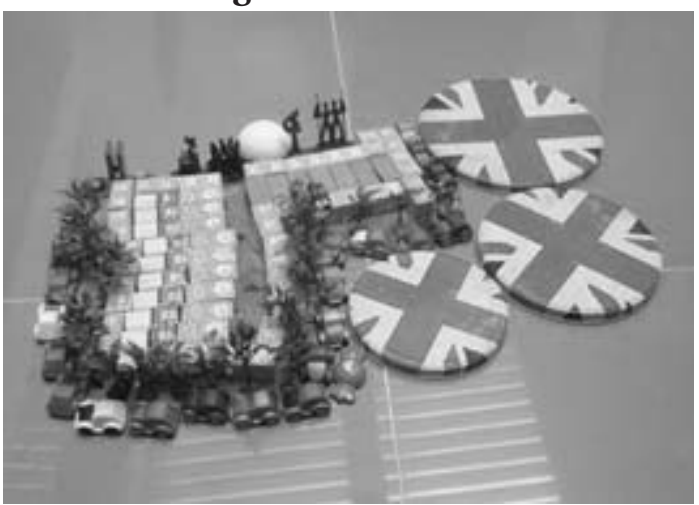

Fonte: Extraído dos dados de pesquisa.

Figura 3 - Lucas

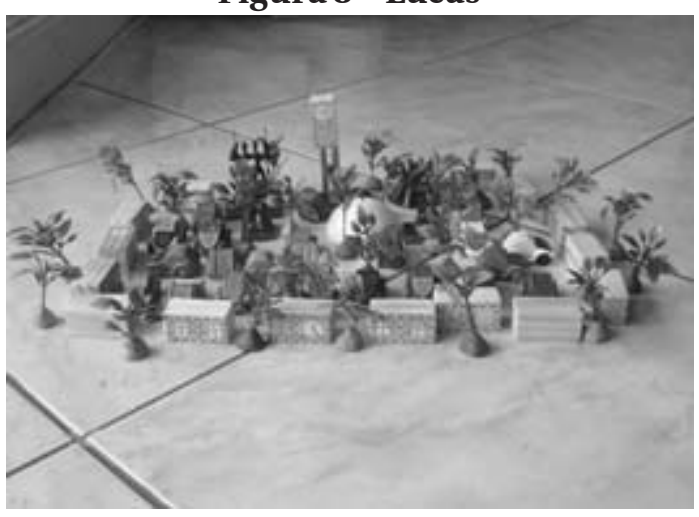

Fonte: Extraído dos dados de pesquisa.

Figura 4-Greg

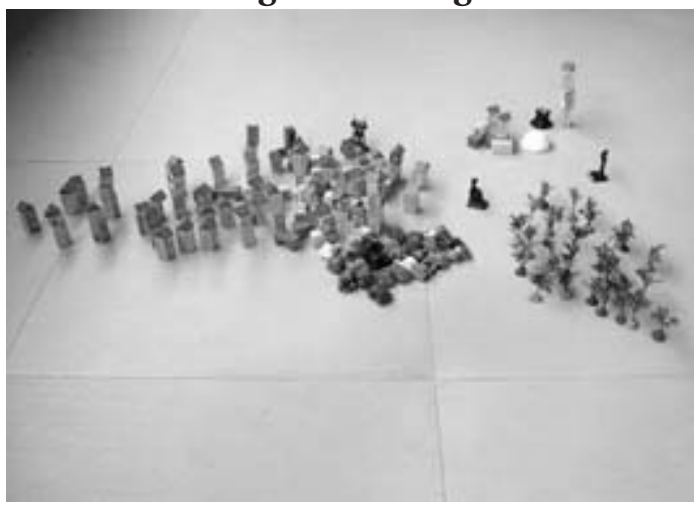

Fonte: Extraído dos dados de pesquisa.

As fotografias mostram que ainda que a cidade compreenda uma área significativamente grande para ser percebida como um todo a par- 
tir de um único ponto de vista, as crianças desde pequenas, têm uma compreensão do que seja esse macro espaço. Mais do que isto, foram capazes de representá-la e projetá-la em uma escala reduzida. Igualmente, tiveram que adotar um ponto de vista diferente daquele que estão acostumadas para realizar tal representação, já que, quando circulam pela cidade, sua visão está mais próxima do chão e podem contemplar as construções de baixo para cima. Entretanto, para construírem suas cidades, as crianças se posicionaram externamente à paisagem e seu olhar passou a ter a direção contrária, ou seja, de cima para baixo.

Posteriormente à construção, e por meio do método de foto-elicitação, as crianças puderam explorar suas cidades a partir de outra representação - a fotográfica - e em outro momento diferente do dia da construção. A narrativa das crianças combinou elementos relacionados à imaginação e às vivências em Brasília e em outras cidades. Os blocos de madeira e demais objetos representaram a paisagem macro de uma cidade, que foi composta com aparelhos sociais, tais como: escola, igreja, museus, parques, parquinhos e meios de transporte. Como afirmaram as crianças: "tem muitas árvores, muitos carros" (Lucas, 30/10/2013 - 30 encontro); "o parquinho, o parquinho, por exemplo, é aqui! [...] aqui são os carros que as pessoas iam entrar nos palcos" (Daniela, 29/10/2013 - 3० encontro); "um poste, um prédio, as árvores, um prédio, um prédio, uma lâmpada, um monte de pessoas juntas” (Amanda, 28/10/2013 - $3^{\circ}$ encontro); "é que a cidade é grande! Carro batendo um no outro, casa caída” (Greg, 07/11/2013 - 30 encontro). As crianças também trataram, sobretudo, de pessoas em suas construções sobre a cidade.

Observamos que as percepções das crianças sobre a cidade, como asseveram Christensen e O’Brien (2003), são construídas por meio da interação com o espaço e com outras pessoas, e, independentemente de seu tamanho, elas criam ligações entre suas experiências de vida e os lugares cotidianos da cidade. Assim, o seu conhecimento sobre e na cidade é motivado pelas experiências individuais e coletivas e são recorrentemente negociadas com outros em diferentes tempos e espaços.

\section{Discussão dos Dados Gerados com Crianças e Mães}

O mapa a seguir (Figura 5) indica os trajetos das crianças, sendo que os de Lucas estão representados pela cor laranja; os de Amanda pela cor roxa, os de Daniela pela cor azul e os de Greg pela cor amarela. 
Figura 5 - Indicação dos trajetos das crianças sobrepostos ao mapa de Brasília

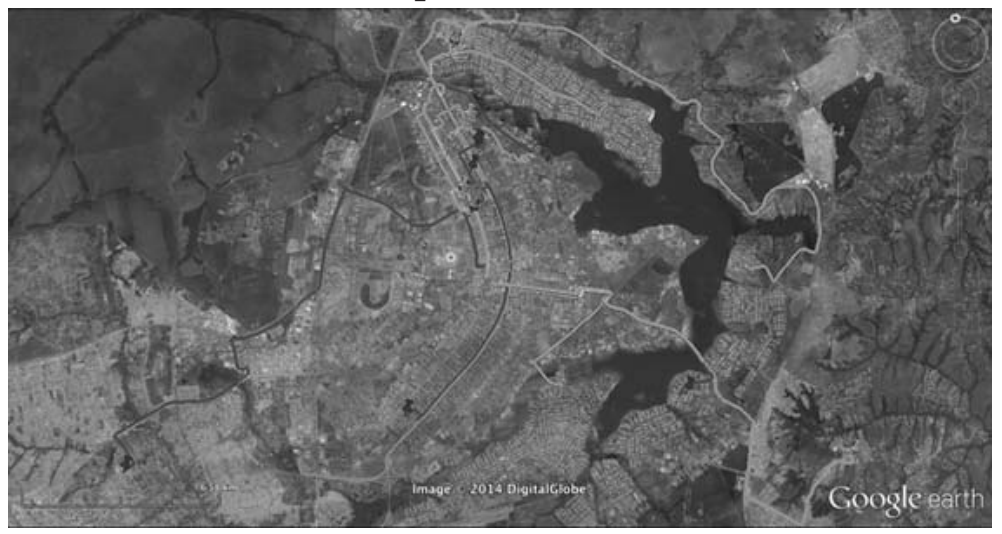

Fonte: Google Earth (2014).

$\mathrm{O}$ mapa indica que as crianças frequentam com assiduidade os seguintes espaços: instituição de Educação Infantil; atividades de capoeira e de natação; casa de avós, de outros familiares e de amigos; parque; parquinho; clube; igreja; restaurante; shoppings; salão de beleza; escola de música; loja e supermercado. Dentre estes, os espaços comuns frequentados pelas crianças e que apareceram em suas cidades são: casa dos avós; instituição de Educação Infantil; e parquinhos. Vale lembrar que os espaços que assumimos como comuns encontram-se no plano da experiência e nem sempre são fisicamente os mesmos.

As experiências das crianças em Brasília e em outras cidades serviram de referência para que elas criassem a sua própria. Na cidade construída foram incorporadas árvores, estátuas, telefone público, poste, suas próprias casas, casas dos amigos, casas dos familiares, casas de festa, Congresso Nacional, escola, igreja, lojas, museus, palcos, parques, parquinhos, pessoas, praia, prédios, restaurantes, ruas, ônibus, carros, acidentes de carro e "tudo que a gente faz" (Daniela, 29/10/2013 - $3^{\circ}$ encontro).

A combinação dos dados gerados com crianças e mães sobre os trajetos comuns mais realizados demonstrou um entendimento apurado das crianças a respeito das dinâmicas e da organização da cidade. Isso porque os trajetos percorridos e os espaços frequentados pelas crianças nos informam sobre interações sociais, ocupações e usos do espaço urbano. Como afirmam Moura e Vasconcelos (2012, p. 89) a cidade se faz e se amplia "[...] por meio dos deslocamentos das pessoas que as compõem".

Segundo Telles (2006), os trajetos percorridos comunicam o ritmo do movimento urbano e demarcam o lugar onde as histórias de vida transcorrem, entrelaçando o espaço e o tempo da experiência coletiva nas diferentes configurações da cidade. Aliada aos trajetos percorridos, identificamos a questão da mobilidade das crianças e o modal recor- 
rentemente utilizado, o que influencia diretamente a percepção sobre os espaços.

A mobilidade urbana constitui um importante elemento para a percepção que as crianças desenvolvem sobre a cidade. A pesquisa de Broberg, Kyttä e Fagerholm (2013) demonstrou que geralmente crianças preferem espaços que possibilitem a elas exercer a mobilidade de forma ativa e independente, e que proporcionem a elas uma relação experimental ao ar livre. Esse mesmo estudo mostra que para as crianças menores os espaços estariam associados a áreas de alta densidade residencial e populacional. A mesma compreensão foi apresentada por Daniela (29/10/2013 - $3^{\circ}$ encontro) ao sugerir a proximidade de sua casa a de seus amigos: "tudo é igual das casas, pertinho uma da outra... aí, é fácil de ir de uma casa para outra [...] daí todos os amigos vinham na minha casa". Nesse sentido, áreas residenciais poderiam ser desenvolvidas de modo a oferecer lugares mais interessantes e de fácil mobilidade para as crianças (Broberg; Kyttä; Fagerholm, 2013).

No presente estudo, as mães indicaram que todos os deslocamentos das crianças são feitos com o acompanhamento de um adulto e em sua maioria são realizados com o uso do automóvel. No entanto, as crianças expressaram seu desejo de transitar e explorar o meio urbano, sugerindo andar sozinhas pelas ruas e de poder "ir em todos os lugares ... eu vou sozinha" (Daniela, 29/10/ 2013 - 30 encontro); "hum, que eu posso ir sozinha: é a rua e no prédio da minha amiga" (Amanda, 28/10/2013 - $3^{\circ}$ encontro).

Neste sentido, mesmo indicando a possibilidade de uma mobilidade mais independente e facilitada por curtas distâncias na cidade construída, as crianças também incorporam carros como principal meio de locomoção. Nas suas cidades observamos tráfego intenso e materializado na organização de carros aglomerados ou em fileiras. Ao ser indagada sobre o porquê dos carros, Amanda (28/10/2013 - $3^{\circ}$ encontro) afirmou: "eles tão indo pro trabalho, e eles trabalham no mesmo lugar, um monte de carro"; Lucas (30/10/2013 - $3^{\circ}$ encontro) argumentou que em sua cidade havia muitos carros e muita gente; apontou para os carros nas fotografias e explicou: "e essa aqui, foi quando as pessoas estavam saindo; essa foi quando as pessoas chegaram e essa, quando as pessoas iam trabalhar".

A utilização do automóvel como meio de locomoção significa imprimir maior velocidade no deslocamento do que quando se caminha. Logo, a percepção dos meandros da cidade fica restrita (Sennet, 2008), e evitar ruas e calçadas contribui para o afastamento da vida pública. Com isto, pessoas passam a atuar como meros espectadores do que acontece ao seu redor nos espaços públicos (Fotel; Thomsen, 2003).

O trânsito, portanto, apresenta-se como elemento que restringe a mobilidade e independência das crianças na cidade, por apresentar vias de tráfego constante e de alta velocidade (Ward, 1978; Hillman, Adams, 1992). Segundo Tonucci (2005, p. 88), “[...] a mobilidade dos adultos aumentou muito e, paralelamente, a mobilidade das crianças reduziu-se até quase desaparecer, em grande parte por causa dos riscos introdu- 
zidos pelos automóveis dirigidos por seus pais". Estes riscos são geralmente assumidos pelos adultos como perigosos às crianças, que por sua vez são consideras incapazes para resolver problemas relacionados a tais questões. De acordo com Ward (1978), Tonucci (1996), Hillman e Adams (1992), os pais têm a ideia de que na rua as crianças estão expostas e vulneráveis a acidentes.

Todas as cidades construídas pelas crianças incorporaram o conjunto total de 22 carros que continha o material oferecido. Os carros e trânsito das cidades tinham diferentes arranjos, Greg (07/11/2013 - $3^{\circ}$ encontro), por exemplo, mencionou a ocorrência de acidentes de trânsito em sua cidade, enquanto Lucas (30/10/2013 - $3^{\circ}$ encontro) comentou: "é... como ela morreu, aí foi atropelada." Essas narrativas indicam que as crianças estão conscientes sobre perigos no trânsito, e fazem associações entre possíveis acidentes de carro com tragédia e morte. Ainda que o deslocamento quotidiano das crianças seja realizado com carro, por meio da construção de suas cidades elas puderam expressar medos e emoções que certamente experienciam em suas vidas.

Todavia, o medo dos adultos de acidentes não pode limitar a utilização das vias, ruas e calçadas pelas crianças. Ward (1978) e Tonucci (2005) afirmam que caminhar a pé pelas ruas ou andar de bicicleta são experiências vitais, e evitar que crianças utilizem esses meios de locomoção não descarta seus perigos, pois a "[...] não familiaridade com os meios de transporte e seus riscos pode ser tão letal quanto uma grande exposição a eles" (Ward, 1978, p. 125, tradução nossa).

Nesse sentido, a proteção das crianças, decorrente das representações sociais da infância, tem as localizado na esfera da vida privada. Historicamente, a infância foi entendida como um período de déficit do desenvolvimento humano, e, portanto, as crianças foram tomadas como indefesas, vulneráveis e dependentes. Esta imagem de infância e de crianças esteve conectada a uma ideia de desenvolvimento biológico e psicológico, que universalizou, de certa forma, uma experiência que é sócio e culturalmente diversa. Gomes e Gouvêa (2008) assinalam que a ressignificação dos espaços sociais tem um grande papel na organização da sociedade moderna ocidental e ambos, espaços e sujeitos, receberam novas conotações.

O espaço privado comum frequentado pelas quatro crianças participantes do estudo e que, ao mesmo tempo, aparece em todas as cidades construídas é a casa dos avós e a experiência vivida apresenta traços similares. Uma dimensão que envolve a casa dos avós é o conjunto de sentimentos vivenciados neste lugar, que é propício à construção de relações afetivas, amigáveis e de brincadeira. Segundo Ramos (2011, p. 285) este é "[...] um lugar no qual as crianças podem viver pequenas e grandes aventuras, experimentando novas situações". Avós e netos criam significados e atribuem valores conjuntamente a seus cantos e paredes, transformando-os em lugares pessoais.

Entretanto, a casa nem sempre é o lugar mais seguro. Tonucci (2005) afirma que, mesmo dentro de casa, muitos perigos são frequentes, como acidentes domésticos, além de que as crianças ficam segrega- 
das a um convívio restrito. Harden (2000) e Pain (2006) ainda mostram que em alguns países a violência às crianças é muito mais presente em lugares privados, como a própria casa, do que em lugares públicos.

Por outro lado, nem sempre o espaço público representa perigo. Pelo contrário, para Gomes e Gouvêa (2008) a relação da criança e a rua constitui parte dos processos de socialização. As autoras tratam este espaço como privilegiado, pois é nele que a criança exerce com maior autonomia suas escolhas, por exemplo, "[...] nas brincadeiras coletivas vivenciam-se conflitos, atos de solidariedade, amizade e rompimento [...] é na rua que tais jogos tornam possível o convívio com o Outro" (Gomes; Gouvêa, 2008, p. 56). Ao tratarem sobre suas cidades, Lucas, Amanda, Daniela e Greg indicaram que espaços públicos seriam por eles utilizados. Amanda (28/10/2013 - $3^{\circ}$ encontro), ao comentar sobre uma viagem, indicou gostar de ir para o Rio de Janeiro por poder frequentar lugares públicos, dentre eles, a praia.

Relacionada a mesma ideia de proteção às crianças, as sociedades têm ao longo do tempo tanto criado espaços específicos destinados à infância quanto outros separados e destinados ao uso dos adultos. Assim, a diferenciação social da infância se reflete na paisagem urbana, com a segregação de lugares para crianças e lugares para adultos (Zeiher, 2003).

Tal postura fragmenta a paisagem urbana, criando limites de ocupação, estes que, para as crianças, se materializaram nos seguintes espaços especializados comuns a todas elas e presentes em suas cidades: a instituição de Educação Infantil, para estudarem; e os parquinhos, para brincarem.

A afirmativa de que a instituição de Educação Infantil representa um espaço especializado repousa sobre sua constituição histórica. Kuhlmann Jr. (2011) indica que no Brasil o processo de criação das instituições de Educação Infantil resultou de uma série de fatores sociais, políticos e até religiosos em prol da assistência à infância. Fatores como a industrialização do país e a consequente urbanização desencadearam vários processos de mudança na organização social da população e da família, em que as mulheres, para garantir uma renda ou ter uma renda maior, inseriram-se no mercado de trabalho. Portanto, uma das primeiras funções das creches era a institucionalização da infância em um espaço formal e organizado para sua guarda e proteção.

Os parquinhos representam igualmente espaços especializados, pois podem se caracterizar como "[...] controle, estacionamento das crianças, e são, por isso, absolutamente distantes de seus interesses e de suas necessidades de criatividade, invenção, movimento rico, encontro, aventura" (Tonucci, 2005, p. 45). Ward (1978) e Jacobs (2000) afirmam que parquinhos, quando planejados pelos adultos, são desenhados com base em um estereótipo do que seja a infância e não destacam características da comunidade local onde estão localizados.

Por outro lado, espaços de uso espontâneo não apareceram como espaços comuns frequentados pelas crianças do presente estudo. Bra- 
sília, uma cidade planejada com muitos espaços sem construções, com pilotis na base dos edifícios que facilitam a circulação das pessoas (Risério, 2012), e até a própria estrutura das Superquadras, permite livre movimento e inúmeras possibilidades de utilização.

Como afirmam Ward (1978), Jacobs (2000) e Tonucci (2005) é preciso garantir às crianças espaços não especializados, pois são neles que podem interagir com quem e o que quiserem. Nesses espaços, as crianças têm a oportunidade de desempenhar um papel ativo e central na tomada de decisão e condução de suas ações, na administração, manutenção e permanência das e nas atividades. Segundo Jacobs (2000, p. 88) "[...] as crianças da cidade precisam [...] de um local perto de casa, ao ar livre, sem um fim específico, onde possam brincar, movimentar-se e adquirir noções do mundo".

Assim as crianças têm a oportunidade de conviver com a comunidade e, ao mesmo tempo, serem assistidas por aqueles que ocupam o mesmo espaço. Tal atitude convoca os adultos a assumir responsabilidade pública pelas crianças, mesmo que não as conheçam. Segundo Tonucci (2005), isto resgataria o sentimento de concidadão, que parece ter se perdido com o tempo.

É certo ainda que mesmo em espaços especializados ou destinados aos adultos, as crianças descobrem cantos e esconderijos. E, de acordo com a variação das condições climáticas, época do ano e disponibilidade, esses cantos e esconderijos são conservados, (re)criados e desfeitos (Rasmussen; Smidt, 2003). Ou seja, as crianças relacionam-se não só com lugares oficiais determinados pelos adultos, mas também com lugares informais, muitas vezes despercebidos.

As crianças ao mesmo tempo negociam os usos de espaços planejados para elas, transformando esses em lugares delas (Jones, 2000; Rasmussen; Smidt, 2003; Müller, 2007). Como estudos mostram, as crianças, de maneira criativa, transgridem limites da cidade impostos por adultos. A cidade, que em sua dimensão completa é um espaço grande demais para ser compreendida de uma só vez, é, aos poucos, ressignificada em partes menores pelas crianças, que tornam seus aqueles lugares que elegem nas "[...] tentativas de se fazerem pertencer, de se tornarem menos invisíveis e resistirem à separação do convívio social mais amplo" (Müller, 2007, p. 180).

Nessa tentativa de fazer parte da cidade e decidir sobre suas próprias lógicas de espacialidades, as crianças participantes do presente estudo tiveram a oportunidade de definir geografias em suas cidades, lidando criativamente com limites e possibilidades. Dispuseram as peças da maneira como quiseram e, posteriormente, durante o exercício de foto-elicitação, puderam sugerir reorganizações. Lucas (30/10/2013 - $3^{\circ}$ encontro) sugeriu como mudança em sua cidade que "faria colocar o parque perto dos carros, o parque da cidade na praia e também um parque de diversões perto do parque da cidade"; ou mesmo Greg (07/11/2013 - $3^{\circ}$ encontro), que colocou em sua cidade todas as casas próximas e disse que, para sua cidade ficar melhor, ele poderia "hum, separar a casa da outra... eu pego uma casa e coloco em outro lugar". 
Como afirma Jones (2000, p. 37, tradução nossa) “[...] as crianças têm algumas oportunidades de decidir suas próprias espacialidades ao invés de permanecerem totalmente nos padrões de geografias dos adultos" e, por isso, criam variações, avançam limites e projetam alternativas.

Uma das sugestões das crianças vai de encontro com o planejamento das cidades para as áreas verdes. Se para os adultos a existência de árvores está conectada ao paisagismo e à mitigação de poluição, e sua função seria a de ornamentar, desintoxicar e proporcionar sombra, para Greg (07/11/2013 - $3^{\circ}$ encontro) as muitas árvores de sua cidade serviriam às crianças como opção de diversão, para "brincar de subir na árvore”. Ou mesmo, a sugestão para uma cidade melhor estaria ligada ao seu bem-estar pessoal, como disse Amanda (28/10/2013 - $3^{\circ}$ encontro) "eu botava um monte de coisa no meu quarto igual de princesa".

Portanto, crianças podem participar de reflexões sobre a cidade que habitam e contribuir para que esta seja um espaço de interações de seus habitantes, independente da idade. Essa afirmação não é nova, mas foi defendida por Ward ainda nos anos de 1970.

\section{Considerações Finais}

Ao reconhecer que as experiências urbanas vividas pelas crianças são plurais, apoiamo-nos em um paradigma teórico-metodológico que considerou prioritariamente a expressão de crianças pequenas, e favoreceu a sua plena participação no processo de geração e de interpretação dos dados.

Portanto, a construção de uma cidade com o uso de diferentes instrumentos aliados aos métodos visuais mostrou-se plausível ao desenvolvimento da pesquisa sobre as experiências urbanas das crianças. Além disso, demonstrou ser uma proposta atrativa e adequada ao entendimento das crianças. Assim, concordamos com Christensen e James (2008, p. 8, tradução nossa), quando afirmam que “[...] crianças não são adultos. Pesquisadores não precisam adotar métodos diferentes per $s e$, mas adotar práticas que ecoem os interesses e rotinas das crianças".

Blaut e Stea (1974) criaram o map-like model para estudar as capacidades geográficas das crianças para construírem noções de espaço. Nossa pesquisa indica que a adaptação do map-like model pode ser uma estratégia possível para incorporar desejos e sugestões das crianças sobre a cidade onde vivem. Uma vez que o proposto foi que cada criança construísse a sua cidade, elas não se sentiram pressionadas a dar uma resposta correta ou seguir um modelo. Também fugimos do estereótipo das atividades escolares, onde é geralmente esperado das crianças que respondam às expectativas do adulto.

Ainda, com a construção das cidades, as crianças puderam transgredir aos padrões impostos pelo seu próprio meio urbano. Por meio da imaginação, elas superaram limitações de qualquer natureza, inserindo em suas cidades "praia” (Lucas, 30/10/2013 - $3^{\circ}$ encontro), "monstro" (Amanda, 28/10/2013 - $3^{\circ}$ encontro), ou mesmo as nomeando como "País 
das Maravilhas" (Lucas, 30/10/2013 - 30 encontro), "México-Inglaterra" (Greg, 07/11/2013 - $3^{\circ}$ encontro).

Ao relacionarmos o que as crianças trataram sobre suas cidades e as indicações das mães sobre os lugares mais frequentados, os trajetos percorridos e o meio de locomoção utilizado, pudemos construir um mapa com os fluxos de circulação das crianças em Brasília. Tal mapa nos mostrou que as crianças concentravam atividades na região onde moravam, qual seja, a Asa Norte de Brasília. No entanto, não deixavam de transitar com certa frequência na Asa Sul, no Lago Sul e no Lago Norte, percorrendo distâncias que variavam aproximadamente entre duzentos metros e vinte e seis quilômetros.

Com o mapeamento dos espaços representados pelas crianças destacamos aqueles que foram comuns a todas; não necessariamente o mesmo espaço físico, mas aqueles que apresentavam a experiência compartilhada. Identificamos que Lucas, Amanda, Daniela e Greg usam cada vez menos os espaços públicos e cada vez mais espaços especializados para desenvolverem atividades, sendo para isso transportadas por seus pais em automóveis.

Os dados gerados nesta investigação correspondem à realidade vivida por uma parcela da população de classe média e média alta que reside no Plano Piloto de Brasília. Neste caso, a utilização de espaços privados, públicos, especializados ou não especializados está relacionada diretamente a fatores econômicos, sociais e culturais.

Observamos que Lucas, Amanda, Daniela e Greg percebem a dinâmica urbana por meio de uma lógica própria, que relacionam ao espaço de trânsito e de moradia, e a atividades recreativas e de alimentação. Isso porque a travessia pela cidade promove a expansão de territórios.

Defendemos, a partir de nosso repertório teórico-metodológico, que crianças são capazes de tratar assuntos que tangem suas vidas. Nesse sentido, é legítimo defender a participação de crianças pequenas nas discussões sobre a cidade que habitam. Ward (1978, p. 31, tradução nossa) chamava a atenção para a dimensão social do espaço da cidade: "[...] uma demanda surge para o espaço social - a demanda de a cidade das crianças ser parte da vida da cidade".

E ainda, apoiamos o argumento de Graue e Walsh (2003) e de Delgado e Müller (2005) de que é urgente pensar o cotidiano da criança em contextos de educação, mas que não necessariamente o da instituição escolar. Portanto, nos parece legítima a investigação sobre a temática cidade e infância.

Recebido em 28 de março de 2015 Aprovado em 26 de abril de 2016

\section{Notas}

1 Agradecemos à Coordenação de Aperfeiçoamento de Pessoal de Nível Superior (CAPES) pelo financiamento da pesquisa que deu origem a este artigo. Igualmente, somos gratas pelos comentários dos/as pareceristas anônimos/ 
as, que motivaram o aprimoramento de ideias para a versão final deste artigo. Qualquer equívoco remanescente é de nossa total responsabilidade.

2 No contexto deste estudo as mães se autodenominaram responsáveis pelas crianças.

3 Vale destacar que este princípio foi respeitado e no curso da pesquisa uma das crianças desistiu. Este fato nos levou a entrar em contato com outra família.

4 O pressuposto da participação das crianças não foi consolidado exclusivamente pelos Estudos da Infância, mas pode ser encontrado na Convenção dos Direitos da Criança (1989) que estabeleceu o direito de a criança expressar sua opinião com liberdade e de ser levada em consideração em assuntos que a ela estejam relacionados.

5 É importante ressaltar que à cada criança foi solicitada a construção de uma cidade, que não necessariamente seria Brasília. Se em um primeiro momento a utilização de miniaturas de pontos turísticos de Brasília mostrou-se contraditória a esta proposta, as próprias crianças deram usos diferentes às funções reais de cada uma delas, o que se mostrou tópico rico de análise.

6 Conforme Morrow (2008) é fundamental proteger o anonimato e a confidencialidade dos nomes dos participantes e dos lugares mencionados durante a pesquisa. Por este motivo, assim como sugere a autora, pedimos que as próprias crianças escolhessem seus pseudônimos e lhes explicamos a razão para tal. Igualmente, os endereços que aparecem neste trabalho não estão completos. Esse procedimento também vai ao encontro da exigência do Comitê de Ética em Pesquisa do Instituto de Ciências Humanas, da Universidade de Brasília (CEP/IH/UnB), que emitiu parecer favorável à realização da pesquisa.

\section{Referências}

ALDERSON, Priscilla. Children as Researchers. In: CHRISTENSEN, Pia; JAMES, Allison (Org.). Research with Children: perspectives and practices. London: Routledge, 2008. P. 276-290.

BANKS, Marcus. Dados Visuais para Pesquisa Qualitativa. Porto Alegre: Artmed, 2004 .

BLAUT, James Morris et al. Mapping as a cultural and cognitive universal. Annals of the Association of American Geographers, Oxford, v. 93, n. 1, p. 165-185, mar. 2003. Disponível em: <http://tinyurl.com/ne8eram>. Acesso em: 13 jun. 2013.

BLAUT, James Morris; STEA, David. Mapping at the Age of Three. The Journal of Geography, New York, v. 73, n. 7, p. 5-9, Oct. 1974. Disponível em: <http://http:// www.tandfonline.com/doi/abs/10.1080/00221347408980311\#preview>. Acesso em: 13 jun. 2013.

BLUEBOND-LANGNER, Myra; KORBIN, Jill. Challenges and Opportunities in the Anthropology of Childhoods: an introduction to children, childhoods, and childhood studies. American Anthropologist, California, v. 109, n. 2, p. 241246, jun. 2007. Disponível em: <http://onlinelibrary.wiley.com/doi/10.1525/ aa.2007.109.2.241/pdf>. Acesso em: 21 set. 2013.

BROBERG, Anna; KYTTÄ, Marketta; FAGERHOLM, Nora. Child-friendly Urban Structures: Bullerby revisited. Journal of Environmental Psychology, v. 35, p. 110-120, jun. 2013. Disponível em: <http://www.sciencedirect.com/science/article/pii/S0272494413000285>. Acesso em: 26 jan. 2014.

278 Educação \& Realidade, Porto Alegre, v. 42, n. 1, p. 261-282, jan./mar. 2017. 
CASTRO, Lucia Rabello de. A Aventura Urbana: crianças e jovens no Rio de Janeiro. Rio de Janeiro: 7 Letras, 2004.

CHRISTENSEN, Pia; JAMES, Allison. Introduction: researching children and childhood: cultures of communication. In: CHRISTENSEN, Pia; JAMES, Allison. (Org.). Research with Children: perspectives and practices. London: Routledge, 2008. P. 1-8.

CHRISTENSEN, Pia; O'BRIEN, Margaret. Children in the City: introducing new perspectives. In: CHRISTENSEN, Pia; O'BRIEN, Margaret (Org.). Children in the City: home, neighbourhood and community. London: Falmer Press, 2003. P. 13-28.

CLARK, Allison. Young Children as Protagonists and the Role of Participatory, Visual Methods in Engaging Multiple Perspectives. American Journal of Community Psychology, v. 46, n. 1-2, p. 115-123, Jun. 2010. Disponível em: <http:// www.ncbi.nlm.nih.gov/pubmed/20532611>. Acesso em: 21 set. 2013.

CLARK-IBÁÑEZ, Marisol. Framing the Social World with Photo-Elicitation Interviews. American Behavioral Scientist, v. 47, n. 12, p. 1507-1527, Aug. 2004. Disponível em: <http://abs.sagepub.com/content/47/12/1507.abstract $>$. Acesso em: 21 set. 2013 .

CORSARO, William Arnold. The Sociology of Childhood. Thousand Oaks: Pine Forge, 1997.

DARBYSHIRE, Philip; MACDOUGALL, Colin; SCHILLER, Wendys. Multiple Methods in Qualitative Research with Children: more insight or just more? Qualitative Research, v. 5, n. 4, p. 417-436, 2005.

DELGADO, Ana Cristina Coll; MÜLLER, Fernanda. Em busca de Metodologias Investigativas com as Crianças e suas Culturas. Cadernos de Pesquisa, São Paulo, v. 35, n. 125, p. 161-179, mai./ago 2005. Disponível em: <http://www.scielo.br/ pdf/cp/v35n125/a0935125.pdf>. Acesso em: 28 mar. 2015.

EINARSDÓTTIR, Jóhanna. Research with Children: methodological andethical challenges. European Early Childhood Education Research Journal, v. 15, n. 2, p. 197-211, 2007.

FOTEL, Trine; THOMSEN, ThyraUth. The Surveillance of Children's Mobility. Surveillance \& Society, Canadá, v. 1, n. 4, p. 535-554, 2003. Disponível em: $<$ http://surveillance-and-society.org/articles $1 \% 284 \% 29 /$ children.pdf $>$. Acesso em: 26 jan. 2014.

FREITAG, Barbara. A Cidade dos Homens. Rio de Janeiro: Tempo Brasileiro, 2002.

GOMES, Ana Maria Rabelo; GOUVÊA, Maria Cristina Soares de. A Criança e a Cidade: entre a sedução e o perigo. In: DEBORTLI, José Alfredo Oliveira; MARTINS, Maria de Fátima. Almeida; MARTINS, Sérgio. (Org.). Infâncias na Metrópole. Belo Horizonte: Editora UFMG, 2008. P. 47-70.

GOOGLE EARTH. Página web. 2014. Disponível em: <http://www.google.com. br/intl/pt-BR/earth/>. Acesso em: 20 out. 2014

GRAUE, Elizabeth; WALSH, Daniel. Investigação Etnográfica com Crianças: teorias, métodos e ética. Lisboa: Fundação Calouste Gulbenkian, 2003.

HARDEN, Jeni. There's no Place like Home: the public/private distinction in children's theorizing of risk and safety. Childhood, London, v. 7, n. 1, p. 4359, Feb. 2000. Disponível em: <http://chd.sagepub.com/content/7/1/43.full. pdf+html>. Acesso em: 26 jan. 2014. 
HILLMAN, Mayer; ADAMS, John. Children's Freedom and Safety. Children's Environments, v. 9, n. 2, p. 12-32, 1992. Disponível em: <http://tinyurl.com/ p36oq2x>. Acesso em: 26 jan. 2014.

JACOBS, Jane. Morte e Vida de Grandes Cidades. São Paulo: Martins Fontes, 2000.

JAMES, Allison; PROUT, Alan. Introduction. In: JAMES, Allison; PROUT, Alan (Org.). Constructing and Reconstructing Childhood. London: Falmer Press, 1990. P. 1-6.

JONES, Owain. Purity, Disorder, Childhood and Space. In: HOLLOWAY, Sarah Lynn; VALENTINE, Gill. Children's Geographies and the New Social Studies of Childhood. In: HOLLOWAY, Sarah Lynn; VALENTINE, Gill (Org.). Children's Geographies: playing, living, learning. London: Routledge, 2000, P. 29-47.

KARSTEN, Lia; VAN VLIET, Willem. Increasing Children's Freedom of Movement Introduction. Journal of Children, Youth and Environments, v. 16, n. 1, p. 69-73, 2006. Disponível em: <http://www.jstor.org/stable/10.7721/chilyoutenvi.16.1.0069>. Acesso em: 03 fev. 2013.

KUHLMANN JÚNIOR, Moysés. Infância e Educação Infantil: uma abordagem histórica. Porto Alegre: Mediação, 2011.

MAYALL, Berry. Towards a Sociology for Childhood: thinking from children's lives. Maidenhead: Open University Press, 2002.

MIKKELSEN, Miguel Romero; CHRISTENSEN, Pia. Is children's Independent Mobility Really Independent? A Study of Children's Mobility Combining Ethnography and GPS/ Mobile Phone Technologies. Mobilities, London, v. 4, n. 1, p. 37-58, Feb. 2009. Disponível em: <http://www.tandfonline.com/doi/abs/10.108 0/17450100802657954\#preview>. Acesso em: 03 fev. 2013.

MIZEN, Phil; OFOSI-KUSI, Yaw. Agency as Vulnerability: accounting for children's movement to the streets of Accra. The Sociological Review, Oxford, v. 61, p. 363-382, May 2013. Disponível em: <http://onlinelibrary.wiley.com/ doi/10.1111/1467-954X.12021/pdf>. Acesso em: 03 fev. 2013.

MORROW, Virginia. Ethical Dilemmas in Research with Children and Young People About their Social Environments. Children's Geographies, v. 6, n. 1, p. 49-61, 2008.

MORROW, Virginia; RICHARDS, Martin. The Ethics of Social Research with Children: an overview. Children and Society, Cambridge, v. 10, p. 90-105, Jun. 1996. Disponível em: <http://preview.tinyurl.com/lk5exqw>. Acesso em: 03 fev. 2013.

MOURA, Cristina Patriota de; VASCONCELOS, Larissa Fernandes Lins de. Trajetórias, Trajetos e "Motilidade" na Universidade de Brasília. Antropolítica, Niterói, n. 32, p. 87-112, 2012. Disponível em: <http://www.revistas.uff.br/index. php/antropolitica/article/view/113>. Acesso em: 14 jul. 2014.

MÜLLER, Fernanda. Retratos da Infância na Cidade de Porto Alegre. 2007. 218 f. Tese (Doutorado em Educação) - Programa de Pós-Graduação em Educação, Universidade Federal do Rio Grande do Sul, Porto Alegre, 2007.

MÜLLER, Fernanda; NUNES, Brasilmar Ferreira. Infância e Cidade: um campo de estudo em desenvolvimento. Educação e Sociedade, Campinas, v. 35, n. 128, p. 629-982, jul.-set. 2014.

NUNES, Brasilmar Ferreira. Sociedade e Infância no Brasil. Brasília: Editora da Universidade de Brasília, 2003.

280 Educação \& Realidade, Porto Alegre, v. 42, n. 1, p. 261-282, jan./mar. 2017. 
PAIN, Rachel. Paranoid Parenting? Rematerializing Risk and Fear for Children. Social \& Cultural Geography, v. 7, n. 2, p. 221-243, Aug. 2006. Disponível em: $<$ http://preview.tinyurl.com/o4vnp38>. Acesso em: 14 jul. 2014.

PINK, Sarah. Sensory Digital Photography: re-thinking 'moving' and the image. Visual Studies, v. 26, n. 1, p. 4-13, Mar. 2011. Disponível em: <http://www.tandfonline.com/doi/abs/10.1080/1472586X.2011.548484\#preview>. Acesso em: 14 jul. 2014.

PROUT, Alan; JAMES, Allison. A New Paradigm for the Sociology of Childhood? Provenance, Promise and Problems. In: JAMES, Allison; PROUT, Alan. Constructing and Reconstructing Childhood. London: Falmer Press, 1990. P. 7-33.

PUNCH, Sam. Research with Children: the same or different from research with adults? Childhood, v. 9, n. 3, p. 321-341, Aug. 2002. Disponível em: <http://www. dreamscanbe.org/Reasearch\%20Page\%20Docs/Punch\%20-\%20research\%20 with\%20children.pdf>. Acesso em: 14 jul. 2014.

RAMOS, Anne Carolina. Meus Avós e Eu: as relações interoperacionais entre avós e netos na perspectiva das crianças. 2011. 463 f. Tese (Doutorado em Educação) - Programa de Pós-Graduação em Educação, Universidade Federal do Rio Grande do Sul, Porto Alegre, 2011.

RASMUSSEN, Kim; SMIDT, Søren. Children in the Neighbourhood: the neighbourhood in the city. In: CHRISTENSEN, Pia; O'BRIEN, Margaret. (Org.). Children in the City: home, neighbourhood and community. London: Falmer Press, 2003. P. 82-100.

RISÉRIO, Antonio. A Cidade no Brasil. São Paulo: Editora 34, 2012.

SENNETT, Richard. Carne e Pedra: o corpo e a cidade na civilização ocidental. Rio de Janeiro: BestBolso, 2008.

TELLES, Vera da Silva. Trajetórias Urbanas: fios de uma descrição da cidade. In: TELLES, Vera da Silva; CABANES, Robert (Org.). Nas Tramas da Cidade: trajetórias urbanas e seus territórios. São Paulo: Associação Editorial Humanitas, 2006. P. 69-116.

TONUCCI, Francesco. La Ciudad de los Niños: um modo nuevo de pensar la ciudad. Buenos Aires, Losada: UNICEF, 1996.

TONUCCI, Francesco. Quando as Crianças Dizem: agora chega! Porto Alegre: Artmed, 2005.

VALENTINE, Gill. “Oh Yes I Can.” “Oh No You Can't”: children and parents understandings of kids competence to negotiate public space safely'. Antipode, Oxford, n. 29, v. 1, p. 65-89, Jan. 1997. Disponível em: <http://www.dreamscanbe.org/Reasearch\%20Page\%20Docs/Punch\%20-\%20research\%20with\%20children.pdf>. Acesso em: 14 out. 2014.

VILELA, Fernando. Aventura Animal. São Paulo: Editora DCL, 2013.

WARD, Colin. The Child in the City. London: Bedford Square Press, 1978.

YOUNG, Lorraine; BARRETT, Hazel. Adapting Visual Methods: action research with Kampala street children. Area, v. 33, n. 2, p. 141-52, Jun. 2001. Disponível em: <http://onlinelibrary.wiley.com/doi/10.1111/1475-4762.00017/>. Acesso em: 14 out. 2014.

ZEIHER, Helga. Shaping Daily Life in Urban Environments. In: CHRISTENSEN, Pia; O'BRIEN, Margaret (Org.). Children in the City: home, neighbourhood and community. London: Falmer Press, 2003. P. 66-81. 
Rhaisa Naiade Pael Farias é estudante do curso de doutorado no Programa de Pós-Graduação em Educação, da Universidade de Brasília. Mestre pelo Programa de Pós-Graduação em Educação, da Universidade de Brasília (2015). Possui pós-graduação lato sensu em Educação Infantil pela Universidade Federal de Mato Grosso do Sul (2012) e graduação em Pedagogia Licenciatura - Habilitação em Educação Infantil pela mesma universidade (2007).

E-mail: rhaisapael@aluno.unb.br

Fernanda Müller é mestre em Educação pela Universidade do Vale do Rio dos Sinos e doutora em Educação pela Universidade Federal do Rio Grande do Sul. Realizou doutorado sanduíche no Centre for Family Research, Universidade de Cambridge. Foi pesquisadora visitante no Center for Language, Interaction and Culture (CLIC)/UCLA (2015-2016). É professora Associada I da Universidade de Brasília.

E-mail: fernandamuller@unb.br 